\title{
Protein Expression Profile and Transcriptome Characterization of Penicillium expansum Induced by Meyerozyma guilliermondii
}

\author{
Qiya Yang, Dhanasekaran Solairaj, Maurice Tibiru Apaliya, Mandour Abdelhai, \\ Marui Zhu, Yuan Yan, and Hongyin Zhang 1
}

School of Food and Biological Engineering, Jiangsu University, Zhenjiang 212013, Jiangsu, China

Correspondence should be addressed to Hongyin Zhang; zhanghongyin126@126.com

Received 23 August 2019; Revised 6 January 2020; Accepted 17 January 2020; Published 11 February 2020

Guest Editor: Manuel J. Serradilla

Copyright ( 2020 Qiya Yang et al. This is an open access article distributed under the Creative Commons Attribution License, which permits unrestricted use, distribution, and reproduction in any medium, provided the original work is properly cited.

\begin{abstract}
Antagonistic yeasts can inhibit fungal growth. In our previous research, Meyerozyma guilliermondii, one of the antagonistic yeasts, exhibited antagonistic activity against Penicillium expansum. However, the mechanisms, especially the molecular mechanisms of inhibiting activity of $M$. guilliermondii, are not clear. In this study, the protein expression profile and transcriptome characterization of $P$. expansum induced by $M$. guilliermondii were investigated. In P. expansum induced by $M$. guilliermondii, 66 proteins were identified as differentially expressed, among them six proteins were upregulated and 60 proteins were downregulated, which were associated with oxidative phosphorylation, ATP synthesis, basal metabolism, and response regulation. Simultaneously, a transcriptomic approach based on RNA-Seq was applied to annotate the genome of $P$. expansum and then studied the changes of gene expression in P. expansum treated with M. guilliermondii. The results showed that differentially expressed genes such as HEAT, Phosphoesterase, Polyketide synthase, ATPase, and Ras-association were significantly downregulated, in contrast to Cytochromes P450, Phosphatidate cytidylyltransferase, and Glutathione S-transferase, which were significantly upregulated. Interestingly, the downregulated differentially expressed proteins and genes have a corresponding relationship; these results revealed that these proteins and genes were important in the growth of $P$. expansum treated with M. guilliermondii.
\end{abstract}

\section{Introduction}

Penicillium expansum is one of the most common pathogens in pears which cause blue mold decay and is able to secrete toxic secondary metabolite patulin (PAT), causing serious food safety problems and harming human health [1]. Recently, there are many strategies that have been employed to control the postharvest diseases of pears; among them chemical and physical methods are contribute the major part. However, both methods have some drawbacks. Therefore, safe and efficient antagonistic yeasts have been a research hotspot in the control of postharvest diseases of pear. Cryptococcus laurentii, Rhodotorula glutinis, Rhodosporidium paludigenum, and Rhodotorula mucilaginosa [2-5] are some effective biocontrol agents against $P$. expansum in pears.

Meyerozyma guilliermondii was reported as an effective antagonistic yeast, which significantly controlled blue mold decay of pears [6] and controlled rice blast disease, cabbage black leaf spot disorder, and bacterial wilt caused by Ralstonia solanacearum, a tomato pathogen [7]. It also showed significant biocontrol of gray mold disease on table grapes caused by Botrytis cinerea [8] and reduced the severity of rot in mangoes during storage [9]. Our previous study showed that blue mold decay caused by $P$. expansum was significantly inhibited by M. guilliermondii without any change in the fruit quality [6]. The biocontrol efficacy increased with increasing yeast concentrations. M. guilliermondii colonized in pears rapidly and maintained relatively higher numbers to compete for nutrient and space with pathogen. M. guilliermondii also enhanced the defense to pathogens in pears [6]. The proteomics and transcriptomics analysis conducted in pears induced by $M$. guilliermondii revealed that $M$. guilliermondii could upregulate the expression of defense-related proteins and genes of pears $[6,10]$. 
Several proteins intervene during the interaction of pathogens with antagonistic yeasts and many of them are crucial to explain the inhibition mechanism of antagonistic yeast. Our previous research reported that more than onethird of the proteins differentially expressed in Talaromyces rugulosus in response to Yarrowia lipolytica were associated with essential metabolism, like phosphoglycerate kinase, nucleoside diphosphate kinase, and so on, which showed that the mechanisms by which $Y$. lipolytica inhibited $T$. rugulosus involved in the essential metabolism [11]. In the same manner, a general analysis of transcriptome and proteome modification of $P$. expansum spores during germination was conducted by Zhou et al. using RNA-Seq and iTRAQ approaches. The corresponding result showed a statistic of 3026 genes and 489 proteins which were differentially expressed [12]. However, as far as we know, the molecular mechanism of $M$. guilliermondii against $P$. expansum has not been studied yet. In the present work, we explored the differentially expressed proteins and several defense-related genes of $P$. expansum cocultured with $M$. guilliermondii through proteomics and transcriptomics analysis and tried to establish the molecular mechanism of $M$. guilliermondii inhibiting the growth of P. expansum.

\section{Materials and Methods}

2.1. Yeast. The antagonist yeast M. guilliermondii (preserved in the China Center for Type Culture Collection, No. M2017270) was isolated from unsprayed orchards. The yeast was cultured in nutrient yeast dextrose broth medium (NYDB, nutrient broth $8 \mathrm{~g} / \mathrm{L}$, yeast extract $5 \mathrm{~g} / \mathrm{L}$, and glucose $10 \mathrm{~g} / \mathrm{L})$ on an incubator shaker $\left(180 \mathrm{rpm}, 28^{\circ} \mathrm{C}\right)$ for $20 \mathrm{~h}$. After incubation, yeast cells were collected by centrifugation $(6918 \times \mathrm{g}$ for $10 \mathrm{~min})$; the pellets were resuspended in sterile water and adjusted to $1 \times 10^{8}$ cells $/ \mathrm{mL}$ concentration with a hemocytometer.

2.2. Pathogen. P. expansum was maintained on potato dextrose agar medium at $4^{\circ} \mathrm{C}$. Before using, the P. expansum strain was inoculated in PDA plates and allowed to grow for seven days at $25^{\circ} \mathrm{C}$ in an incubator. After seven days, the spores were removed from the Petri dish and suspended in sterile distilled water. A hemocytometer was used to adjust spore concentrations to $1 \times 10^{7}$ spores $/ \mathrm{mL}$.

2.3. Analysis of the Differentially Expressed Proteins of $P$. expansum and $P$. expansum Incubated with M. guilliermondii. Initially, $1 \mathrm{~mL}$ of spore suspension $\left(1 \times 10^{7}\right.$ spores $\left./ \mathrm{mL}\right)$ of $P$. expansum was added to $100 \mathrm{~mL}$ of PDB inside $500 \mathrm{~mL}$ Erlenmeyer volumetric flasks and incubated for two days at $25^{\circ} \mathrm{C}, 120 \mathrm{rpm}$. Then, $1 \mathrm{~mL}$ suspension of $M$. guilliermondii at $1 \times 10^{8}$ cells $/ \mathrm{mL}$ was added. After $1 \mathrm{~d}$ incubation, the mycelia were collected and the protein was extracted according to the method described by Yang et al. [11].

2-DE and Image Analysis were conducted in accordance with the method delineated by Yang et al. and Zhang et al. with some modifications $[11,13,14]$. Isoelectric focusing was used to separate proteins in GE Ettan IPGphor 3, according to the manufacturer's instructions [14].

Identification of Proteins. Mass calibrations were carried out with a standard peptide mixture. Mass spectra were acquired using Matrix-Assisted Laser Desorption/Ionization Timeof-Flight (MALDI-TOF) mass spectrometer (Bruker Daltonics, Germany). The identification of the vast majority of proteins was performed using search engine MASCOT Peptide Mass Fingerprint of Matrix Science and compared with NCBInr and Swiss-Prot databases. The parameters used for MS search were taxonomy, all series; allowed modifications, carbamidomethyl of cysteine (fixed), oxidation of methionine (variable); and peptide tolerance, $\pm 0.3 \mathrm{Da}$. Only the highest Mowse score was considered as the most probable identification and was significant $(P<0.05)$ when protein scores were greater than 88 (NCBInr) or 70 (SwissProt) [14].

2.4. Transcriptomic Analysis of P. expansum and P. expansum Incubated with $M$. guilliermondii. RNA from the mycelia was extracted in accordance with the prescription of Sangon Co., Shanghai, China, with little modifications [14]. The concentration of RNA was detected by Qubit ${ }^{\circledR}$ RNA Assay Kit in Qubit ${ }^{\circledR}$ 2.0 Fluorometer (Life Technologies, Carlsbad, CA, USA). Nanodrop 2000 spectrophotometer (Thermo Scientific, Waltham, MA, USA) was used to determine the purity of RNA. RNA Nano 6000 Assay Kit of the Bioanalyzer 2100 system was used (Agilent Technologies, Santa Clara, CA, USA) to assess the integrity of the RNA. The samples that met the experimental requirements were used for the next steps [14].

2.4.1. Transcriptome Analysis. Each RNA sample was used to perform RNA-Seq. tRNA-Seq libraries were sequenced on an Illumina HiSeq 2500 platform to generate $125 \mathrm{bp} / 150 \mathrm{bp}$ single-ended reads [14].

\subsubsection{Bioinformatics Analysis of RNA-Seq Data.} Transcriptomic data were assembled, after high-quality sequencing data were acquired, using Trinity [14]. The UniGene sequences of $P$. expansum and $P$. expansum incubated with $M$. guilliermondii were searched using BLAST and compared with those obtained using the NR, Swiss-Prot, $\mathrm{GO}$, and KEGG databases for the confirmation of amino acid sequence.

2.5. Validation of RNA-Seq Data by RT-qPCR. RT-qPCR analysis was performed using RNA extracted from $P$. expansum and $P$. expansum incubated with $M$. guilliermondii, in order to validate the data obtained from RNASeq. The genes and their specific primers used for RT-qPCR were listed in Supplementary Table 1 and analysis was performed using a Bio-Rad CFX-96 Real-Time PCR System (Bio-Rad, USA). The reaction system that was conducted in accordance with the method delineated by Yang et al. [14] comprised of $12.5 \mu \mathrm{L} \mathrm{SYBR}{ }^{\circledR}$ Premix Ex Taq ${ }^{\mathrm{TM}}$ II $(2 \mathrm{x}) ; 0.5 \mu \mathrm{L}$ 
50x Rox Reference Dye II; $1 \mu \mathrm{L}$ Primer-F; $1 \mu \mathrm{L}$ Primer-R; $2 \mu \mathrm{L}$ cDNA; and $8 \mu \mathrm{L} \mathrm{ddH}_{2} \mathrm{O}$. The thermocycler conditions were set at an initial denaturation temperature of $95^{\circ} \mathrm{C}$ for $30 \mathrm{~s}$, followed by 40 cycles of $95^{\circ} \mathrm{C}$ for $5 \mathrm{~s}$ and finally, one cycle of $60^{\circ} \mathrm{C}$ for $34 \mathrm{~s}$ and $72^{\circ} \mathrm{C}$ for $30 \mathrm{~s}$. To normalize the gene expression level, Actin gene from P. expansum was used as an internal control. The RT-qPCR analysis was repeated three times with three technical replicates. The relative expression level of the sample gene was calculated using a $2^{-\Delta \Delta \mathrm{CT}}$ method [10].

2.6. Statistical Analysis. The data were analyzed by analysis of variance (ANOVA) using the statistical program SPSS/PC version 8 (SPSS Inc., Chicago, Illinois, USA), and Duncan's multiple range test was used for mean separation. The statistical significance was assessed at $P<0.05$.

\section{Results}

3.1. Identification of Differentially Expressed Proteins of P. expansum. The whole protein expression of $P$. expansum and $P$. expansum treated with by $M$. guilliermondii was shown in Figure 1. In each gel, a total of 66 differentially expressed (average fold change $\geq 2, p<0.05$ ) proteins were identified. Just 6 of them were significantly upregulated, while 60 proteins were significantly downregulated. Furthermore, 43 spots which showed the best resolution among the significantly differentially expressed proteins were analyzed for identification by mass spectrometry (MS). An elaborated report on lowercase letters about the names of peptides is in Table 1.

The basic information of 43 differentially expressed protein spots, comprising isoelectric point, molecular weight, and peptide matches, was assigned to a class. As reported in Table 1, several proteins were related to secondary metabolite synthesis, which included polyketide synthase (spot 20), enoylreductase (spot 32). Some proteins were associated with ATP synthesis, which included ATP hydrolase (ATPase), delta/epsilon subunit F1, N-terminal (spot 17), ATPase, F1 complex beta subunit/V1 complex, and C-terminal (spot 38). Some proteins were also associated with cellular basal metabolism, which included phosphoesterase (spot 36), glyceraldehyde/erythrose phosphate dehydrogenase family (spot 44), and phosphoglycerate kinase (spot 41) and some proteins were found to be associated with environmental immune response, which included heat shock $70 \mathrm{kDa}$ protein (spot 24); these downregulated proteins were all associated with the basal metabolic process, response, and regulation of $P$. expansum. Gene ontology (GO) functional annotation examination was performed for the whole identified proteins, which exposed a broad number of molecular functions like biological processes and cellular components (Figure 2). The results indicated that the largest group of biological processes was metabolic process (25 proteins) and cellular process ( 25 proteins), and the other two biological processes were single-organism process (16 proteins) and biological regulation (7 proteins); these proteins were all related to the basal metabolic process. All identified proteins were annotated to categories. There were 98 and 90 proteins involved in cellular and biological processes as well as 56 proteins involved in molecular functioning, respectively. All the differentially expressed proteins were mainly involved in basic metabolism (30\%), binding $(23 \%)$, catalytic $(21 \%)$, transporter $(7 \%)$, and hypothetical (7\%) processes (Figure 3).

3.2. Transcriptomic Analysis by RNA-Seq. The transcriptomes of $P$. expansum and $P$. expansum cocultured with M. guilliermondii were analyzed using RNA-Seq technology. The transcriptome data indicated a total number of $13 \mathrm{~Gb}$ clean data; the Q30 base percentage was $89.75 \%$ and $89.92 \%$ (Table 2). A total of 434 differentially expressed genes (DEGs) were compiled, among them 408 genes were upregulated and 26 genes were downregulated in the $P$. expansum treated with $M$. guilliermondii ( $\log _{2}$ (fold change) $\mid \geq 2$, FDR $<0.05$ ) (Table 3). Using gene ontology (GO), these DEGs were clustered by gene function (Figure 4). The cellular components and molecular functions were further analyzed, each contained 19 subgroups and the biological processes contained 22 subgroups. The main categories concerning cellular component contained cell $(23.9 \%)$, cell part (23.9\%), organelle (13.9\%), and membrane (13.4\%). The highest percentage of identified differentially expressed genes under molecular function category included catalytic activity (46.1\%) and binding (38.5\%), whereas the percentage in the biological process category was as follows: basic metabolism (21.0\%), cellular process $(20.2 \%)$, single-organism process (19.0\%), and biological regulation (18.5\%). The most enriched KEGG pathway of $P$. expansum transcriptome analysis was shown in Figure 5. There were four pathways including cellular processes, environmental information processing, genetic information processing, and metabolism. In the cellular processes, there were 5 DEGs in cell growth and death, 16 DEGs in transport and catabolism. In the environmental information processing, there were $22 \mathrm{DEGs}$ in folding, sorting, and degradation, 6 DEGs in transcription, and 6 DEGs in translation. In metabolism, the highest pathway is carbohydrate metabolism (32.14\%), energy metabolism (17.26\%), amino acid metabolism (16.07\%), and lipid metabolism (14.28\%).

3.3. Validation of RNA-Seq Data by RT-qPCR. The genes identified as key DEGs of $P$. expansum, due to M. guilliermondii coculturing, which are involved in basal metabolism were evaluated by real-time-quantitative polymerase chain reaction (RT-qPCR) (Table 4, Figure 6). From the result of RNA-Seq (Figure 6), the expression levels of TRINITY_DN7572_c0_g2 (Phosphoesterase), TRINITY_DN10607_c0_g1 (Polyketide synthase, enoylreductase), TRINITY_DN3524_c0_g2 (ATPase, F0/V0 complex, subunit C), TRINITY_DN7527_c0_g1 (ATPase, F1/A1 complex, alpha subunit, N-terminal), TRINITY_DN5224_c0_g4 (HEAT, type 2) were significantly different. Expression levels of these five genes were significantly decreased, which were $0.53,0.21,0.44,0.41$, and 0.32 times lower than those in control group, respectively. The results of RT-qPCR were consistent with the gene expression results of RNA-Seq. 


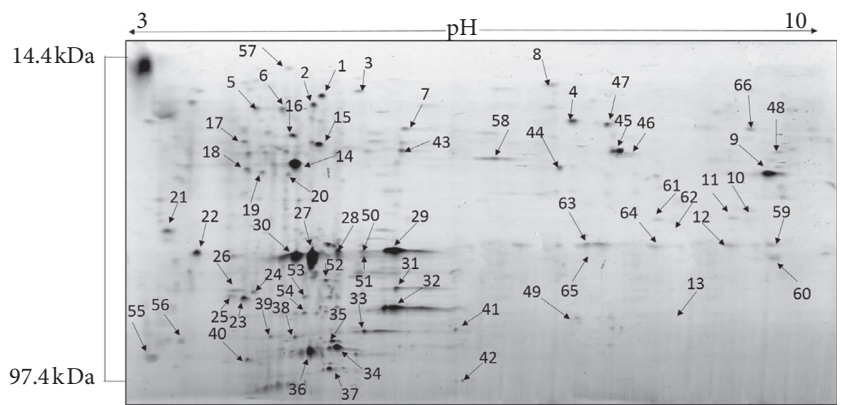

(a)

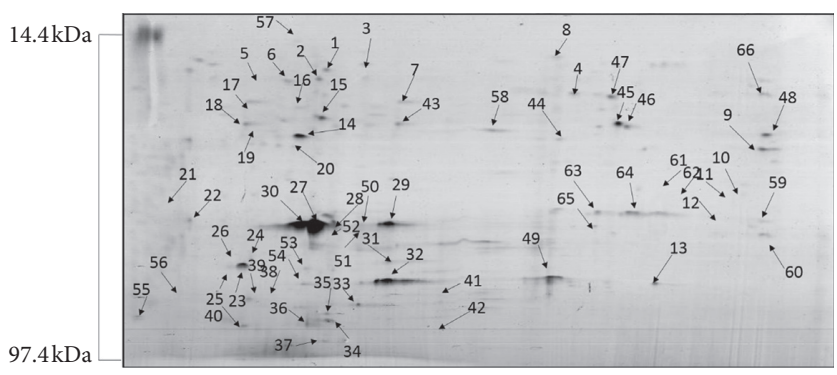

(b)

Figure 1: 2-D gels of differentially expressed proteins of P. expansum treated with sterile distilled water and M. guilliermondii. (a) P. expansum protein expressed after treatment with sterile distilled water. (b) P. expansum protein expressed after treatment with M. guilliermondii.

TABle 1: Identification of differentially expressed proteins in P. expansum after different treatments.

\begin{tabular}{|c|c|c|c|c|c|c|}
\hline $\begin{array}{l}\text { Protein } \\
\text { spot }\end{array}$ & Protein name & $\begin{array}{c}\text { NCBI } \\
\text { accession }\end{array}$ & Mass & PI & Species & Score \\
\hline$\downarrow 1$ & Hypothetical protein PDIG_00280 & gi|425781927 & 10361 & 5.28 & Penicillium digitatum & 397 \\
\hline$\downarrow 2$ & Thioredoxin & gi|700488450 & 11987 & 5.12 & Penicillium expansum & 79 \\
\hline$\downarrow 4$ & 40 S ribosomal protein $S 21$ & gi| 584409470 & 10008 & 7.77 & Penicillium roqueforti & 162 \\
\hline$\downarrow 6$ & Profiling & gi|768690728 & 13945 & 4.63 & Penicillium solitum & 96 \\
\hline$\downarrow 7$ & Pc21g11730 & gi|255954903 & 13188 & 5.59 & $\begin{array}{l}\text { Penicillium rubens } \\
\text { Wisconsin }\end{array}$ & 148 \\
\hline$\downarrow 8$ & UBI 3 fusion protein (149 AA) & gi|3086 & 18932 & 9.82 & Neurospora crassa & 86 \\
\hline$\downarrow 9$ & Cyclophilin-type peptidyl-prolyl cis-trans isomerase & gi|700447277 & 28161 & 8.91 & Penicillium expansum & 222 \\
\hline$\downarrow 14$ & Redoxin & gi|700458248 & 18736 & 8.69 & Penicillium expansum & 115 \\
\hline$\downarrow 15$ & Pc06g01290 & gi|255930353 & 14246 & 5.39 & $\begin{array}{l}\text { Penicillium rubens } \\
\text { Wisconsin }\end{array}$ & 166 \\
\hline$\downarrow 16$ & Aegerolysin & gi|700452244 & 15646 & 4.92 & Penicillium expansum & 124 \\
\hline$\downarrow 17$ & ATPase, F1 complex, delta/epsilon subunit, N-terminal & gi|700448219 & 17639 & 5.19 & Penicillium expansum & 171 \\
\hline$\downarrow 20$ & Polyketide synthase, enoylreductase & gi|700457792 & 37941 & 5.6 & Penicillium expansum & 116 \\
\hline$\downarrow 22$ & Hypothetical protein BC1G_05980 & gi|154311893 & 22792 & 4.29 & Botrytis cinerea & 98 \\
\hline$\uparrow 23$ & Peptidase aspartic, catalytic & gi|700446168 & 43688 & 5.57 & Penicillium expansum & 669 \\
\hline$\downarrow 24$ & Heat shock $70 \mathrm{kDa}$ protein & gi| 425774732 & 69862 & 5.03 & Penicillium digitatum & 271 \\
\hline$\downarrow 25$ & Elongation factor 1 beta central acidic region, eukaryote & gi|700446479 & 25224 & 4.47 & Penicillium expansum & 159 \\
\hline$\downarrow 26$ & $\begin{array}{l}\text { Nascent polypeptide-associated complex (NAC) subunit, } \\
\text { putative }\end{array}$ & gi|425773866 & 21921 & 4.75 & Penicillium digitatum & 156 \\
\hline$\downarrow 28$ & Pc22g10220 & gi|255948526 & 67030 & 5.32 & $\begin{array}{l}\text { Penicillium rubens } \\
\text { Wisconsin }\end{array}$ & 221 \\
\hline$\downarrow 29$ & Glucose/ribitol dehydrogenase & gi|700452783 & 28635 & 6.97 & Penicillium expansum & 240 \\
\hline$\downarrow 31$ & Ketose-bisphosphate aldolas & gi|700454353 & 39308 & 4.91 & Penicillium expansum & 390 \\
\hline$\downarrow 32$ & Polyketide synthase, enoylreductase & gi|700457792 & 37941 & 5.6 & Penicillium expansum & 316 \\
\hline$\downarrow 33$ & Enolase BAC82549-Penicillium chrysogenum & gi|255938796 & 47250 & 5.26 & $\begin{array}{l}\text { Penicillium rubens } \\
\text { Wisconsin }\end{array}$ & 313 \\
\hline$\downarrow 34$ & & gi|700454561 & 61890 & 5.61 & Penicillium expansum & 368 \\
\hline$\downarrow 35$ & Glutamate carboxypeptidase, putative & gi| 425778622 & 53077 & 5.34 & Penicillium digitatum & 450 \\
\hline$\downarrow 36$ & Phosphoesterase & gi|700450431 & 50668 & 5.18 & Penicillium expansum & 166 \\
\hline$\downarrow 37$ & Chaperone DnaK & gi|700451345 & 72353 & 5.51 & Penicillium expansum & 356 \\
\hline$\downarrow 38$ & ATPase, F1 complex beta subunit/V1 complex, C-terminal & gi|700446699 & 55307 & 5.34 & Penicillium expansum & 535 \\
\hline$\downarrow 39$ & Hypothetical protein PDIG_75600 & gi| 425768525 & 61928 & 4.99 & Penicillium digitatum & 135 \\
\hline$\downarrow 40$ & Protein disulfide isomerase & gi|700453960 & 56761 & 4.66 & Penicillium expansum & 112 \\
\hline$\downarrow 41$ & Phosphoglycerate kinase & gi|417486 & 44103 & 6.07 & Penicillium citrinum & 96 \\
\hline$\downarrow 43$ & Lithostathine precursor & gi|45430003 & 19720 & 5.75 & Bos taurus & 222 \\
\hline$\downarrow 44$ & $\begin{array}{l}\text { Glyceraldehyde/erythrose phosphate dehydrogenase } \\
\text { family }\end{array}$ & gi|700447332 & 36225 & 6.01 & Penicillium expansum & 126 \\
\hline$\downarrow 45$ & Nucleoside diphosphate kinase & gi|425772472 & 16737 & 7.77 & Penicillium digitatum & 259 \\
\hline$\downarrow 47$ & FK506-binding protein & gi|584415065 & 13203 & 6.41 & Penicillium roqueforti & 328 \\
\hline
\end{tabular}


TABLE 1: Continued.

\begin{tabular}{|c|c|c|c|c|c|c|}
\hline $\begin{array}{l}\text { Protein } \\
\text { spot }\end{array}$ & Protein name & $\begin{array}{c}\text { NCBI } \\
\text { accession }\end{array}$ & Mass & PI & Species & Score \\
\hline$\uparrow 48$ & Pc16g13060 & gi|255941672 & 18109 & 6.91 & $\begin{array}{c}\text { Penicillium rubens } \\
\text { Wisconsin }\end{array}$ & 256 \\
\hline$\uparrow 49$ & Pc21g22820 & gi|255956993 & 37501 & 8.07 & $\begin{array}{c}\text { Penicillium rubens } \\
\text { Wisconsin }\end{array}$ & 215 \\
\hline$\downarrow 51$ & $\begin{array}{c}\text { Thiamine pyrophosphate enzyme, C-terminal TPP- } \\
\text { binding }\end{array}$ & gi|700446530 & 63440 & 5.69 & Penicillium expansum & 185 \\
\hline$\downarrow 52$ & Proteasome subunit alpha type 3 & gi|70991357 & 29766 & 5.19 & Aspergillus fumigatus & 82 \\
\hline$\downarrow 53$ & 2-Phosphoglycerate dehydratase & gi|74662366 & 47264 & 5.14 & Penicillium chrysogenum & 246 \\
\hline$\downarrow 54$ & Flagellin & gi|736787790 & 38621 & 5.09 & Ewingella americana & 229 \\
\hline$\downarrow 60$ & Pc22g17950 & gi|255949874 & 36031 & 9.47 & $\begin{array}{l}\text { Penicillium rubens } \\
\text { Wisconsin }\end{array}$ & 75 \\
\hline$\downarrow 61$ & Nucleic acid-binding, OB-fold & gi|700454689 & 58601 & 6.54 & Penicillium expansum & 70 \\
\hline$\downarrow 62$ & Phosphoglycerate kinase & gi|417486 & 44103 & 6.07 & Penicillium citrinum & 177 \\
\hline
\end{tabular}

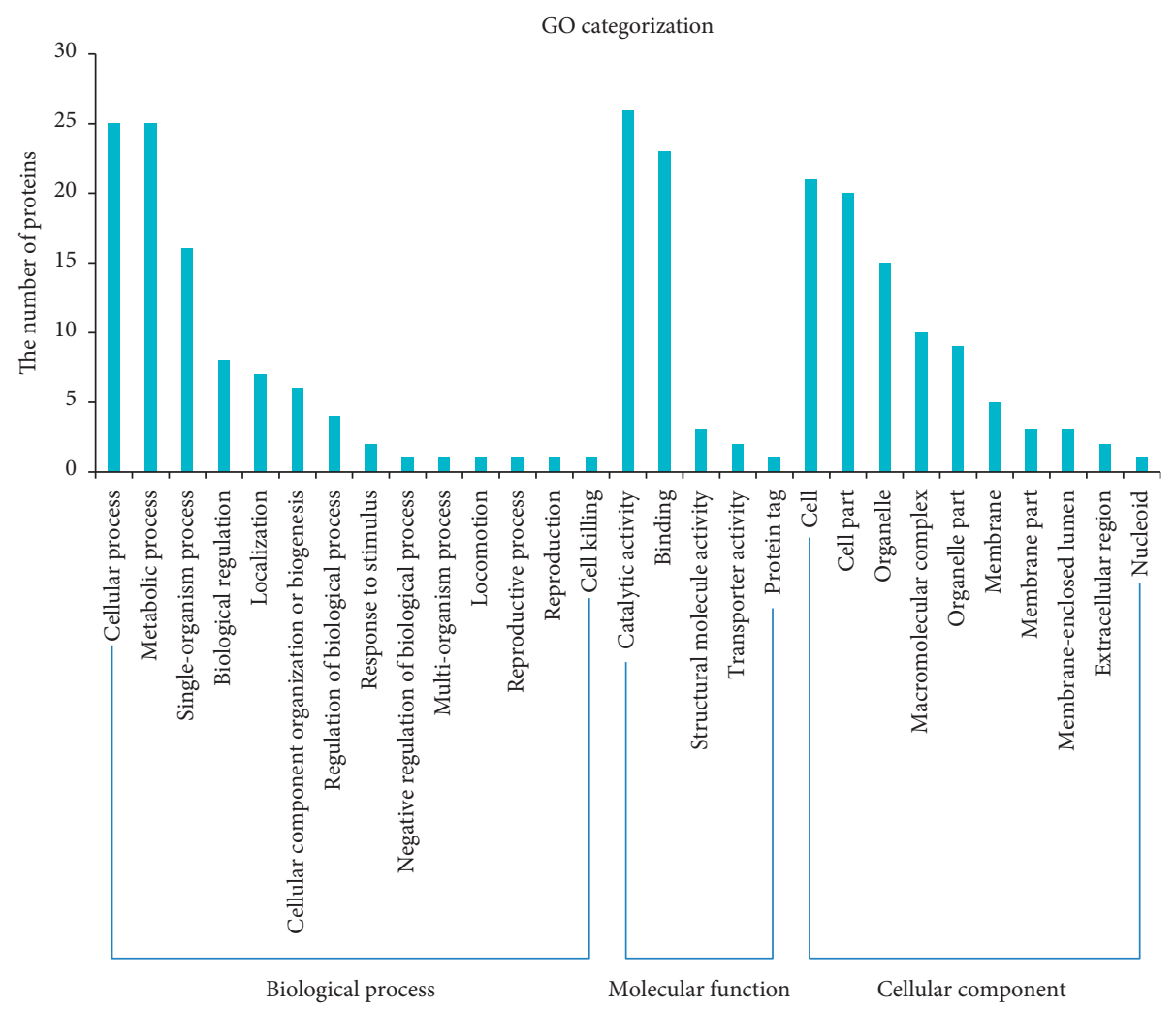

FIGURE 2: GO categorization of differentially expressed proteins in P. expansum after different treatments. The proteins were categorized according to the annotation of GO, and the number of each category is displayed based on biological process, molecular functions, and cellular components.

\section{Discussion}

Blue mold decay caused by P. expansum is a serious disease in fruit, in particular pear fruits [6]. Recently, some pathogenic strains developed resistance against synthetic fungicides; therefore, researchers concern about environmental and food safety. Antagonistic yeasts are gaining considerable attention due to their beneficial environmental and food safety characteristics and also controlling postharvest diseases in fruits. Integrating transcriptomic and proteomic data to achieve meaningful insights into $P$. expansum inhibited by $M$. guilliermondii has rarely been reported. Therefore, the present work highlights the protein expression profile and transcriptomic changes of $P$. expansum in order to explore the molecular inhibitory mechanism of $M$. guilliermondii. GO categorization was compared between differentially expressed proteins from 2-DE and differentially expressed genes from RNA-Seq analysis. A majority of differentially expressed proteins and genes were involved in secondary metabolite synthesis, ATP synthesis, cellular basal metabolism, environmental immune response, genetic information processing, and metabolism. 


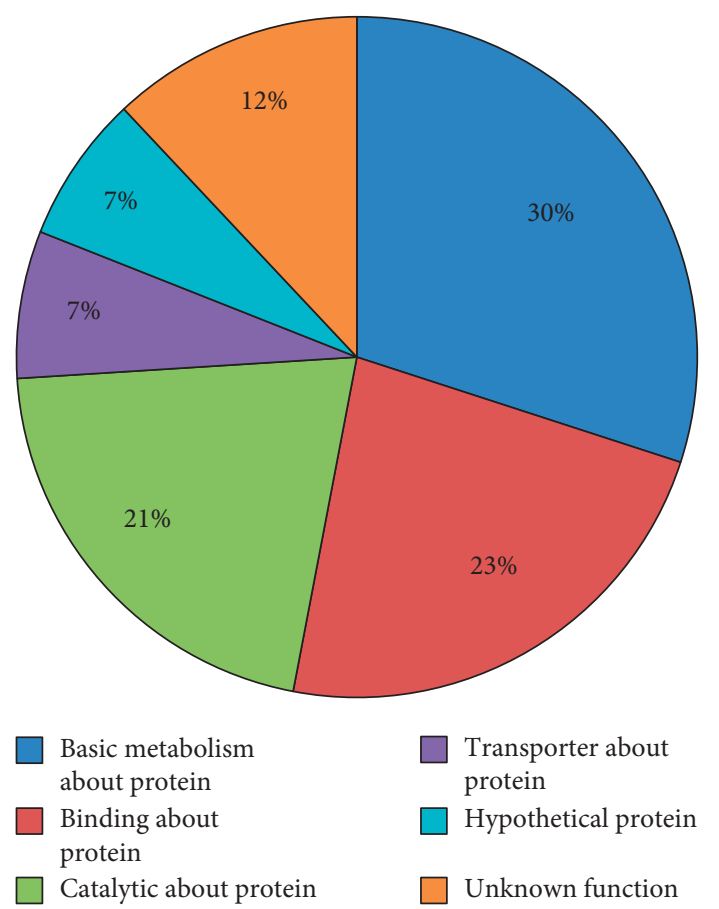

FIGURE 3: Functional classification of differentially expressed proteins in $P$. expansum after different treatments.

There are many enzymes responsible for synthesis of ATP; ATPase was considered as the most important enzyme in ATP synthesis. In the current investigation, protein ATPase, F1 complex (spots 17 and 38) corresponding with ATPase, F0/V0 complex, subunit $C$ and ATPase, F1/A1 complex, alpha subunit, $N$-terminal, were all downregulated. Similar trend was observed in transcriptomic analysis; the gene corresponding to ATPase, F0/VO complex, subunit $C$ (TRINITY_DN3524_c0_g2, TRINITY_DN7527_c0_g1) was downregulated significantly. Yang et al. reported that the protein related to $\mathrm{ABC}$ transporters (PAAT), which is a novel ATPase and a trans-regulator of mitochondrial ABC transporters, is responsible for cell survival and maintenance of mitochondrial homeostasis [15]. Additionally, Yang et al. reported that the poplar buds active fraction (PBAF) depresses ATPase activity of Penicillium italicum and explained that the inhibitory effect of PBAF on fungal growth is due to the inhibition of ATPase by PBAF [16]. Castellote et al. investigated the molecular expression of Geotrichum candidum overripening of Reblochon-type cheese and observed that the genes responsible for F1F0 ATP synthase subunits (ATP1, ATP2, ATP5, and ATP7) were quiescent which leads to the reduced ATP production and consumption, normally less energy needed for quiescent cells [17]. From these reports, we anticipated that ATPase did not only provide energy for the basic metabolism of $P$. expansum, but also was the main carrier for the life activities of $P$. expansum. In the present investigation, the ATP activity of $P$. expansum treated with $M$. guilliermondii was reduced; thus, the energy supply was prevented and the growth was inhibited.

Heat shock protein 70 (HSP70) was a main part of the cell's machinery for protein folding and contributed to protection of cells against stress $[18,19]$. In addition to the involvement of HSP70 in maintaining and improving the protein integrity, it directly inhibits apoptosis [20]. In our results, the heat shock $70 \mathrm{kDa}$ protein (point 24) corresponded with the transcriptome genes Heat, type 2 (TRINITY_DN5224_c0_g4), and both were downregulated. The intracellular heat shock protein and gene expression of $P$. expansum was downregulated because of the effect of $M$. guilliermondii. Zhang et al. studied the underlying molecular mechanisms of HSP70 in the environmental stress response of coral through transcriptome expression and reported that HSP70 (PdHSP70) was an essential stress regulatory protein in the stony coral Pocillopora damicornis; therefore, diverse environmental stress could induce HSP70 mRNA expression and its activity could remain stable under heat stress [21]. Kim et al. identified 10 Calmodulin (CaM)-binding protein in Beauveria bassiana; one of its targets was HSP70 and their results also suggested that ATP was involved in the inhibition of molecular interaction between $\mathrm{CaM}$ and HSP70 [22]. From the earlier studies, it was evidenced that downregulation of HSP70 weakens the adaptation ability and immune response of $P$. expansum to the external environment; the cells were apoptotic and the growth of $P$. expansum was inhibited by M. guilliermondii.

In biological systems, phosphoesterase plays a vital role in DNA fragmentation, RNA replication, human body medicine, metabolism, chemotherapy, and bioremediation $[23,24]$. In the present results, the phosphoesterase protein (point 36) that corresponded with the transcriptome genes phosphoesterase (TRINITY_DN431_c0_g2) was downregulated. It could be speculated that the phosphate kinase activity of $P$. expansum was reduced and substance metabolism process was blocked due to the effect of M. guilliermondii, which resulted in shortage of phosphate needed for the survival of $P$. expansum and thus the normal life activity of $P$. expansum was inhibited by $M$. guilliermondii.

Polyketide synthases (PKSs) belong to a multidomainenzyme or complex-enzyme family which are responsible for the production of polyketides, a major class of secondary metabolites, in microorganisms, plants, and some animal lineages $[25,26]$. Polyketide synthases also play a definite role in the production of naturally occurring small molecules employed in chemotherapy [27]; many of the commonly used antibiotics and other industrially important polyketides were produced by polyketide synthases [28]. Our results demonstrated that the polyketide synthase, enoylreductase protein (point 20 and point 32), was downregulated. RNASeq analysis also showed that the gene responsible for polyketide synthases (TRINITY_DN10607_c0_g1) was downregulated significantly. Moreover, in $P$. expansum, the polyketide synthases are involved in the synthesis of patulin, a hazardous mycotoxin derived from polyketides [29]. Role of patulin in the pathogenicity and virulence of $P$. expansum was already proved in postharvest apples infected by $P$. expansum [30]. Patulin synthesis in P. expansum is carried out by a biosynthetic gene cluster consisted of 15 genes (PatA-PatO) in ten different enzymatic reactions [31]. Among them, the initial seven reactions in patulin synthesis are catalyzed by polyketide synthases [32]. Therefore, our 
TABle 2: Transcriptome sequencing data of P. expansum treated with M. guilliermondii (Y) and P. expansum (CK).

\begin{tabular}{lccccc}
\hline Samples & JSHY-ID & Read number & Base number & GC content $(\%)$ & $\% \geq Q 30$ \\
\hline CK & T01 & 23336546 & 7000963800 & 54.33 & 89.75 \\
Y & T02 & 20001194 & 6000358200 & 53.89 & 89.92 \\
\hline
\end{tabular}

TABLE 3: The number of differentially expressed genes of $P$. expansum treated with M. guilliermondii $(\mathrm{Y})$ and $P$. expansum $(\mathrm{CK})$.

\begin{tabular}{lccc}
\hline DEG set & DEG number & Upregulated & Downregulated \\
\hline CK_vs._Y & 434 & 408 & 26 \\
\hline
\end{tabular}

results may confirm that the polyketide synthase activity of $P$. expansum was reduced due to the inhibition of $M$. guilliermondii; thus the normal synthesis of patulin and other secondary metabolites of $P$. expansum was prevented. Likewise, Ras-association gene (TRINITY_DN6243_c0_g3) was also downregulated in $P$. expansum treated with $M$. guilliermondii. In most of the pathogenic fungi, Ras pathway signaling is determined as critical virulence factor [33]. The Ras pathway signaling is involved in pathogenesis, morphological transitions, nutrient sensing and acquisition, sexual reproduction, and stress responses of fungi [34]. The results also evidenced that the pathogenicity and virulence of $P$. expansum was weakened, and its growth was eventually inhibited by M. guilliermondii.

Phosphatidate cytidylyltransferase is an enzyme, involved in lipid transport and metabolism, that majorly takes part in the phospholipid metabolism in cell membranes. Lipids are essential components in membrane trafficking, cytoskeletal rearrangement, and secretion, which are reported to be the important mechanisms of stress tolerance [35]. In the present transcriptomic analysis, the gene responsible for phosphatidate cytidylyltransferase (TRINITY_DN3203_c0_g2) was upregulated in P. expansum. Bernardo et al. reported the upregulation and accumulation of phosphatidate cytidylyltransferase during drought stress in the roots of wheat [36]. Other than stress tolerance, phosphatidate cytidylyltransferase was also known for its role in antibiotic resistance mechanism against antimicrobial lipopeptides [37]. It was evidenced that in order to overcome the stress created by M. guilliermondii and to resist the activity of the yeast, the phosphatidate cytidylyltransferase gene was upregulated in $P$. expansum. In the same way, the upregulation of striatin, N-terminal (TRINITY_DN6439_c0_g1) was observed in the transcriptomic analysis. Striatin orthologs were directly related to the virulence of some filamentous fungi like Fusarium verticillioides and F. graminearum against plants [38]. Hence, we hypothesized that though some pathogenic related factors were inhibited by $M$. guilliermondii, some other genes related to stress tolerance and virulence were upregulated.

To sustain cellular redox homeostasis, the thioredoxin system assures a crucial function and the thioredoxin protein (point 2) was downregulated in the present study. Viefhues et al. indicated that thioredoxin had a strict influence on virulence of Botrytis cinerea, proving that redox processes were determinant for host-pathogen interactions in this pathogen; in addition, the balanced redox status established by the thioredoxin system was vital for growth and pathogenesis of $B$. cinerea [39]. Ianiri et al. investigated the modification of gene expression in Sporobolomyces sp. under patulin exposition; they noted the major increase in transcript levels of antioxidant molecules glutathione and thioredoxin in Sporobolomyces genes. The research team further subclassified the metabolic process of patulin exposed group and found that 6 DEGs were involved in glutathione biosynthesis, and 3 DEGs were involved in the thioredoxin system [40]. In contrast, by downregulation in the present study, we speculated that the thioredoxin system, which is involved in the defense response to ROS, was inhibited by M. guilliermondii and the growth of $P$. expansum was controlled.

The ribosomal S21 protein as part of eukaryotic ribosomes had proved to be strongly related to ribosome-associated protein in human and Drosophila cells [41-43]. In our results, the 40S ribosomal protein S21 (spot 4) was downregulated and was involved in nucleotide transport and metabolism. Sato et al. examined the functions of the ribosomal proteins S0 and S21 in Schizosaccharomyces pombe and found that the ribosomal protein played a major physiological role in 18s rRNA stability which was essential for the survival of $S$. pombe cells [44]. Therefore, we hypothesized that, in the presence of M. guilliermondii, $40 \mathrm{~S}$ ribosomal protein S21 P. expansum was inhibited so that the growth and survival of the fungi was reduced dramatically.

Cytochromes P450 was distributed in almost all organisms and involved in diverse metabolic processes, which were highly diverse and contributed to the metabolism of xenobiotic compounds such as bioconversion of xenobiotics, biotransformation of drugs, and so on [45]. In the current investigation, the Cytochrome P450 (TRINITY_DN5730_c0_g1) was upregulated. Trippe et al. studied the genetic underpinnings which permit Graphium sp. to catalyze the early step in the alkane and ether oxidation pathway; furthermore, they identified $C Y P 52 L_{1}$ as an alkaneoxidizing Cytochrome P450, posttranscriptional ds-RNAmediated gene silencing of $C Y P 52 L_{1}$ and proved that the gene silencing disrupted the ability of Graphium sp. to grow on alkanes and ethers [46]. Similarly, our results revealed that the upregulation of Cytochrome P450 (TRINITY_DN5730_c0_g1) could be activated by the basic metabolic process of $P$. expansum after it was cocultured with $M$. guilliermondii.

Glutathione S-transferases (GSTs) are well known for their capacity to reduce the oxidative potency of xenobiotic substrates for the purpose of detoxification $[47,48]$. The main role of GSTs is to reduce the toxicity of xenobiotics compounds by catalyzing the GSH nucleophilic attack on electrophilic atoms of said nonpolar xenobiotic substrates, thereby avoiding their interaction with essential cellular proteins as well as nucleic acids [49]. In the present study, the Glutathione S-transferase (TRINITY_DN8139_c0_g1) 


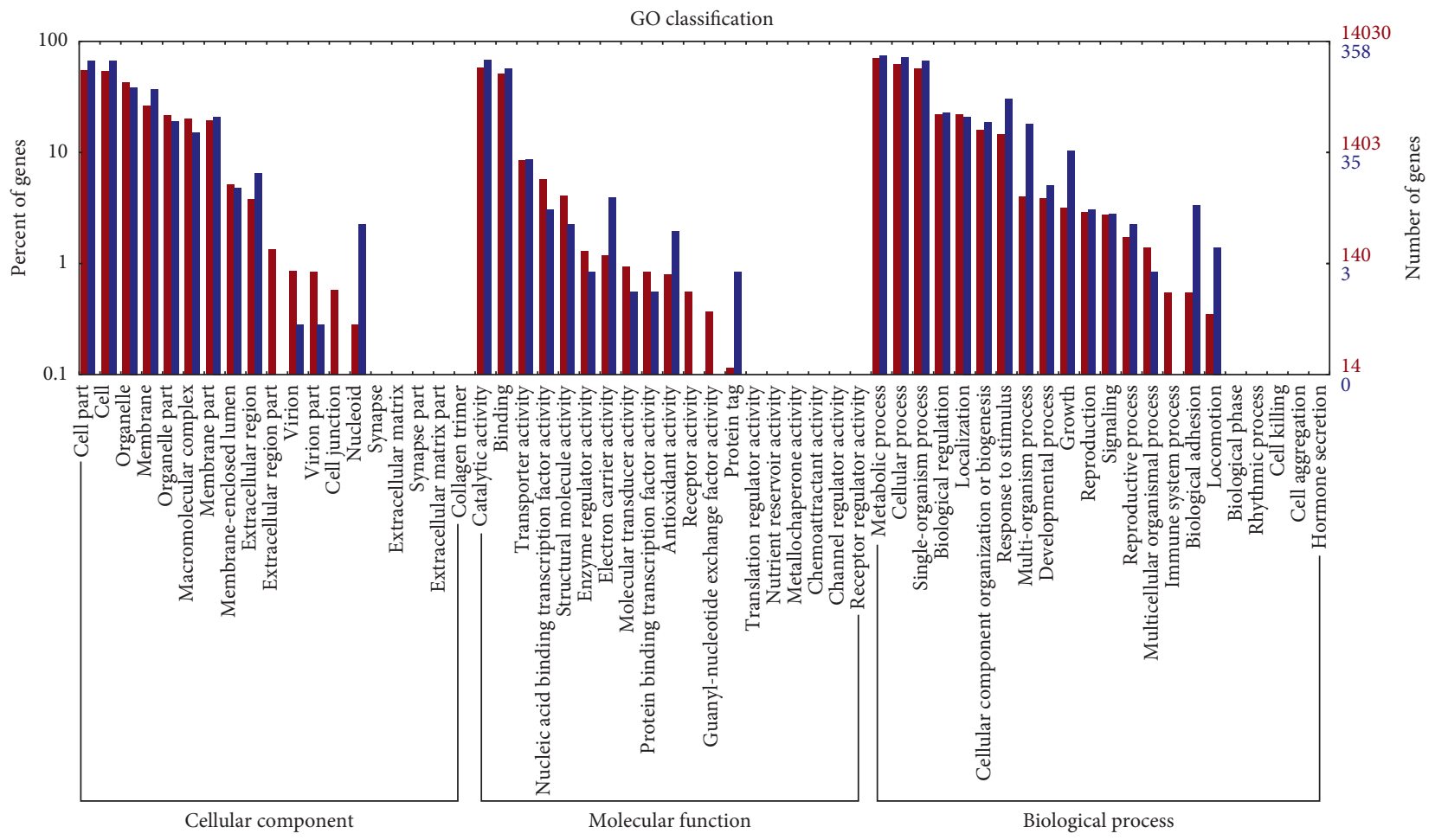

- All gene

- DIFF gene

FiguRe 4: GO categorization of differentially expressed genes in P. expansum.

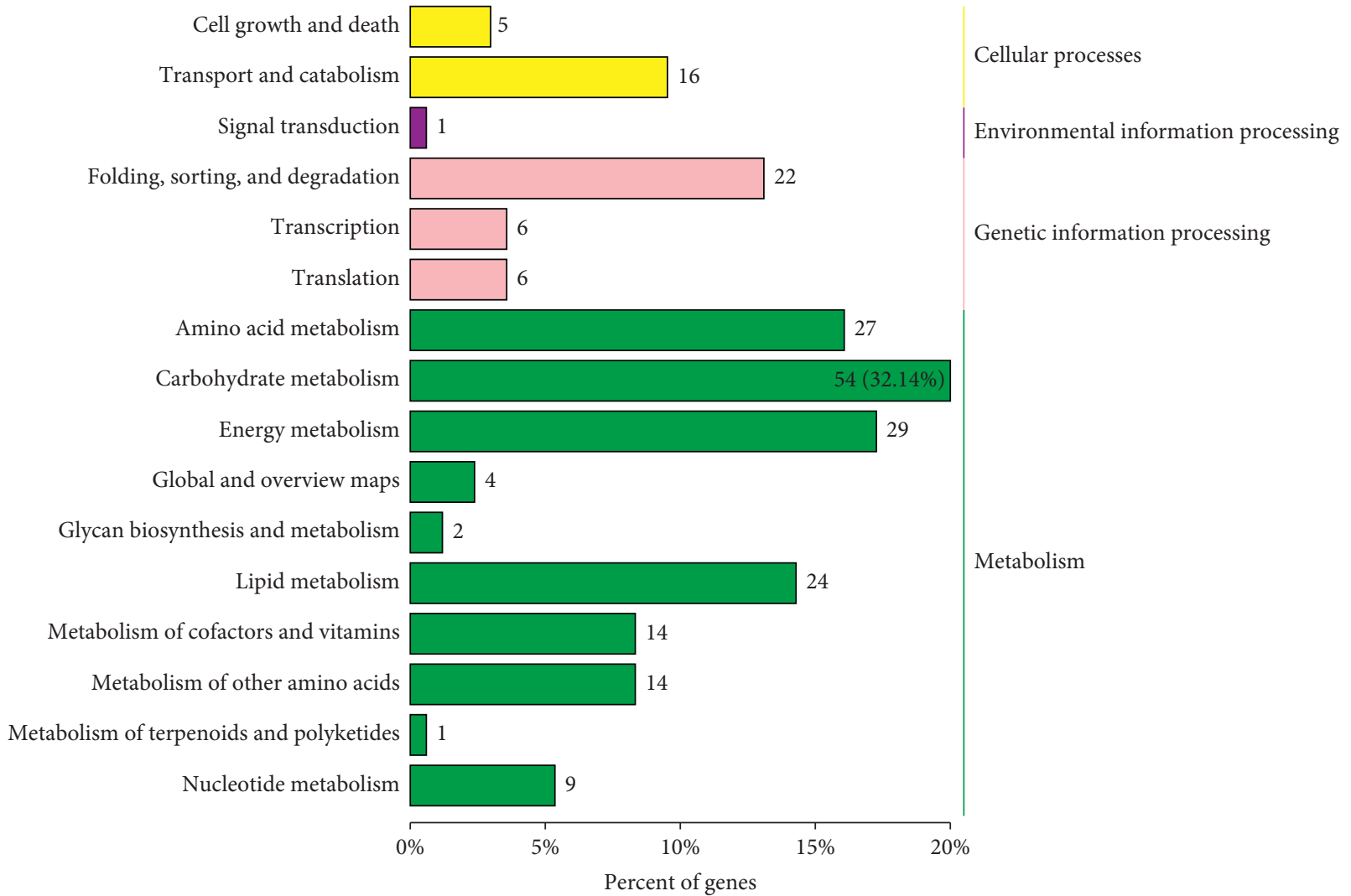

FIGURE 5: KEGG categorization of differentially expressed genes in P. expansum. 
TABle 4: Differentially expressed genes of P. expansum treated with M. guilliermondii (Y) and P. expansum (CK). FDR $<0.05$ and $\log _{2}$ fold change $\geq 2$ were considered statistically significant.

\begin{tabular}{|c|c|c|c|c|}
\hline Functional classification & Gene ID & Gene annotation & $\begin{array}{l}\text { Fold } \\
\text { change }\end{array}$ & FDR \\
\hline $\begin{array}{l}\text { Secondary metabolites biosynthesis, } \\
\text { transport, and catabolism }\end{array}$ & TRINITY_DN10607_c0_g1 & Polyketide synthase & -9.638 & 0.0144304 \\
\hline ATP hydrolysis coupled proton transport & TRINITY_DN3524_c0_g2 & ATPase, F0/V0 complex, subunit $C$ & -9.654 & 0.0498454 \\
\hline ATP hydrolysis coupled proton transport & TRINITY_DN7527_c0_g1 & $\begin{array}{c}\text { ATPase, F1/A1 complex, alpha subunit, } \\
\text { N-terminal }\end{array}$ & -9.882 & 0.0450140 \\
\hline Signal transduction mechanisms & TRINITY_DN6243_c0_g3 & Ras-association & -10.069 & 0.0414577 \\
\hline Cell wall/membrane/envelope biogenesis & TRINITY_DN431_c0_g2 & Phosphoesterase & -10.667 & 0.0296615 \\
\hline Cell organelle organization & TRINITY_DN5224_c0_g4 & HEAT, type 2 & -10.048 & 0.0415417 \\
\hline Ascospore formation & TRINITY_DN6439_c0_g1 & Striatin, N-terminal & 12.128 & 0.0144304 \\
\hline Lipid transport and metabolism & TRINITY_DN3203_c0_g2 & Phosphatidate cytidylyltransferase & 10.235 & 0.0381777 \\
\hline $\begin{array}{l}\text { Secondary metabolites biosynthesis, } \\
\text { transport, and catabolism }\end{array}$ & TRINITY_DN5730_c0_g1 & Cytochrome P450, E-class, group & 13.040 & 0.0138044 \\
\hline $\begin{array}{l}\text { Posttranslational modification, protein } \\
\text { turnover, chaperones }\end{array}$ & TRINITY_DN8139_c0_g1 & $\begin{array}{c}\text { Glutathione S-transferase/chloride } \\
\text { channel, C-terminal }\end{array}$ & 11.707 & 0.0138044 \\
\hline
\end{tabular}

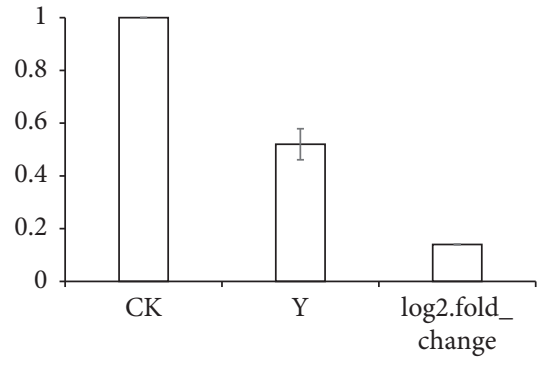

(a)

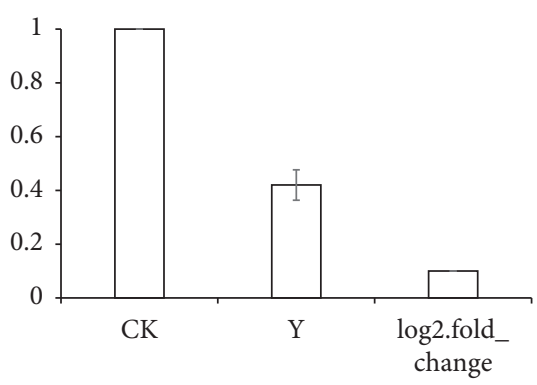

(d)

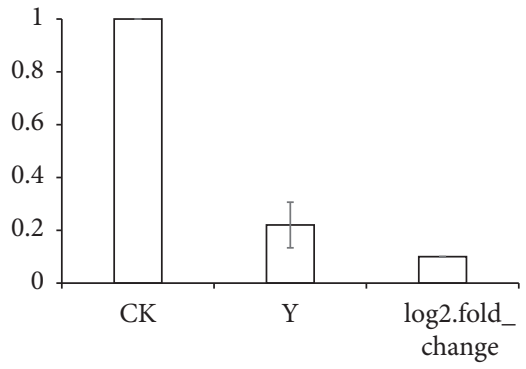

(b)

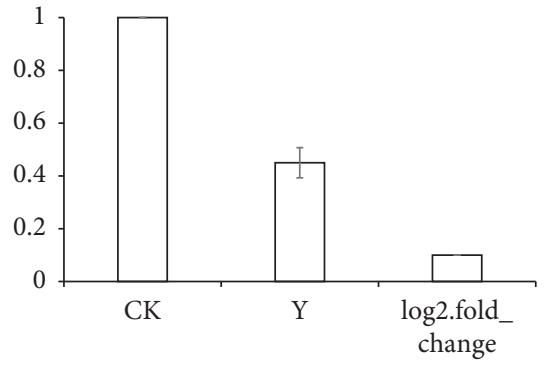

(c)

FIgURE 6: Verification of differentially expressed genes by RT-qPCR. Treatments: CK: P. expansum treated with sterile distilled water, Y: $P$. expansum treated with M. guilliermondii. Values are means of two independent experiments. Error bars represent the standard error of the mean. (a) Phosphoesterase. (b) Polyketide synthase, enoylreductase. (c) ATPase, F0/V0 complex, subunit C. (d) ATPase, F1/V1 complex, alpha subunit, N-terminal. (e) HEAT, type 2.

was upregulated. Ouyang et al. showed that citral possibly triggered a reduction in the mitochondrial membrane potential (MMP), intracellular ATP, and glutathione content, in contrast to an increase in the glutathione S-transferase activity and the accumulation of reactive oxygen species (ROS); these results indicated that the addition of citral probably leads to the oxidative damage of Penicillium digitatum and inhibited the growth of $P$. digitatum [50]. Hence, from the upregulation of GST, it could be postulated that the GST activity was activated in order to overcome the increased ROS in the presence of M. guilliermondii. The results also evidenced that $M$. guilliermondii created oxidative stress against $P$. expansum; hence, the level of GST (antioxidative enzyme) was increased. Overall, we have hypothesized that though some stress tolerance mechanism of $P$. expansum was activated, M. guilliermondii inhibit the growth and pathogenesis of $P$. expansum by downregulating certain pathways of virulence mechanism, cellular signal transduction, mycotoxin production, and cell organization.

On the other hand, the biocontrol efficacy of M. guilliermondii and pathogenic ability of $P$. expansum might be altered under availability of different nutritional sources 
such as carbon $(\mathrm{C})$, nitrogen $(\mathrm{N})$, and environmental factors such as $\mathrm{pH}$ value, temperature, and water activity. Jianjie et al. studied the effect of nutrition and environmental factors on the biocontrol potential of Esteya vermicola and reported that both of them have great influence on the biocontrol potential [51]. Similarly, the growth and mycotoxin producing ability of $P$. expansum was altered by different glucose-containing sugars, complex $\mathrm{N}$ sources, and acidic conditions were favorable conditions for patulin production [52]. Since the stress tolerance of M. guilliermondii in extreme salinity stress was proved already [53], we speculated that the antagonistic potential of $M$. guilliermondii might be worthy in a diverse range of nutritional supplements and environmental factors. However, in the future prospect, the effect of various nutritional sources and environmental factors in the biocontrol mechanism of $M$. guilliermondii are needed to be studied.

In conclusion, several genes, such as HEAT, Phosphoesterase, Polyketide synthase, and ATPase, disclosed a corresponding relationship between the transcript and protein levels and revealed that those genes could play an important role in the growth regulation of $P$. expansum. Moreover, the data from transcriptomic and proteomic analysis discussed in the present study have not only underlined a set of genes and proteins that were essential in the growth of $P$. expansum, but also gave fundamental knowledge of molecular mechanism behind the inhibitory activity of M. guilliermondii against the growth of mold.

\section{Data Availability}

The data used to support the findings of this study are included within the article.

\section{Conflicts of Interest}

The authors have no conflicts of interest to declare.

\section{Acknowledgments}

This work was supported by the Natural Science Foundation of the Jiangsu Higher Education Institutions of China (18KJB550002), National Natural Science Foundation of China (31571899), "333 High-level Personnel Training Project" of Jiangsu Province (BRA2017442), and Jiangsu "Blue Project" of Colleges and Universities.

\section{Supplementary Materials}

Supplementary Table 1: primer design of basal metabolism and response regulation genes in P. expansum. (Supplementary Materials)

\section{References}

[1] Q. Y. Yang, H. Y. Zhang, X. Y. Zhang, X. F. Zheng, and J. Y. Qian, "Phytic acid enhances biocontrol activity of Rhodotorula mucilaginosa against Penicillium expansum contamination and patulin production in apples," Frontiers in Microbiology, vol. 6, 2015.
[2] M. Lin, Y. Zhang, C. Sun et al., "Characterization and overexpression of RHO1 from Cryptococcus laurentii ZJU10 activates CWI signaling pathway on enhancing the inhibition of blue mold on pears," International Journal of Food Microbiology, vol. 278, pp. 1-10, 2018.

[3] H. Y. Zhang, L. Wang, Y. Dong, S. Jiang, H. H. Zhang, and X. D. Zheng, "Control of postharvest pear diseases using Rhodotorula glutinis and its effects on postharvest quality parameters," International Journal of Food Microbiology, vol. 126, no. 1-2, pp. 167-171, 2008.

[4] R. Zhu, T. Yu, S. Guo, H. Hu, X. Zheng, and P. Karlovsky, "Effect of the yeast Rhodosporidium paludigenum on postharvest decay and patulin accumulation in apples and pears," Journal of Food Protection, vol. 78, no. 1, pp. 157-163, 2015.

[5] H. Hu, F. Yan, C. Wilson, Q. Shen, and X. Zheng, "The ability of a cold-adapted Rhodotorula mucilaginosa strain from Tibet to control blue mold in pear fruit," Antonie Van Leeuwenhoek, vol. 108, no. 6, pp. 1391-1404, 2015.

[6] Y. Yan, X. Zhang, X. Zheng et al., "Control of postharvest blue mold decay in pears by Meyerozyma guilliermondii and it's effects on the protein expression profile of pears," Postharvest Biology and Technology, vol. 136, pp. 124-131, 2018.

[7] M. M. Elsharkawy, M. Nakatani, M. Nishimura, T. Arakawa, M. Shimizu, and M. Hyakumachi, "Suppression of rice blast, cabbage black leaf spot, and tomato bacterial wilt diseases by Meyerozyma guilliermondii TA-2 and the nature of protection," Acta Agriculturae Scandinavica, Section B-Soil \& Plant Science, vol. 65, no. 7, pp. 629-636, 2015.

[8] K. Kasfi, P. Taheri, B. Jafarpour, and S. Tarighi, "Identification of epiphytic yeasts and bacteria with potential for biocontrol of grey mold disease on table grapes caused by Botrytis cinerea," Spanish Journal of Agricultural Research, vol. 16, no. 1, 2018.

[9] D. Terao, K. de Lima Nechet, and B. de Almeida HalfeldVieira, "Competitive and colony layer formation ability as key mechanisms by yeasts for the control Botryosphaeria dothidea fruit rot of mango," Tropical Plant Pathology, vol. 42, no. 6, pp. 451-457, 2017.

[10] Y. Yan, X. Zheng, M. T. Apaliya, H. Yang, and H. Zhang, "Transcriptome characterization and expression profile of defense-related genes in pear induced by Meyerozyma guilliermondii," Postharvest Biology and Technology, vol. 141, pp. 63-70, 2018.

[11] Q. Yang, H. Wang, H. Zhang et al., "Effect of Yarrowia lipolytica on postharvest decay of grapes caused by Talaromyces rugulosus and the protein expression profile of T. rugulosus," Postharvest Biology and Technology, vol. 126, pp. 15-22, 2017.

[12] T. Zhou, X. H. Wang, J. Luo et al., "Identification of differentially expressed genes involved in spore germination of Penicillium expansum by comparative transcriptome and proteome approaches," Microbiologyopen, vol. 7, no. 3, 2018.

[13] H. Zhang, M. Dong, Q. Yang, M. T. Apaliya, J. Li, and X. Zhang, "Biodegradation of zearalenone by Saccharomyces cerevisiae: possible involvement of ZEN responsive proteins of the yeast," Journal of Proteomics, vol. 143, pp. 416-423, 2016.

[14] Q. Y. Yang, J. W. Diao, N. N. G. Legrand et al., "The protein expression profile and transcriptome characterization of Pichia caribbica induced by ascorbic acid under the oxidative stress," Biological Control, vol. 142, 2020.

[15] X. Yang, J. Yang, L. Li et al., "PAAT, a novel ATPase and trans-regulator of mitochondrial $\mathrm{ABC}$ transporters, is critically involved in the maintenance of mitochondrial homeostasis," The FASEB Journal, vol. 28, no. 11, pp. 4821-4834, 2014. 
[16] S. Yang, L. Liu, D. Li et al., "Use of active extracts of poplar buds against Penicillium italicum and possible modes of action," Food Chemistry, vol. 196, pp. 610-618, 2016.

[17] J. Castellote, S. Fraud, F. Irlinger et al., "Investigation of Geotrichum candidum gene expression during the ripening of Reblochon-type cheese by reverse transcription-quantitative PCR," International Journal of Food Microbiology, vol. 194, pp. 54-61, 2015.

[18] M. Tavaria, T. Gabriele, I. Kola, and R. L. Anderson, "A hitchhiker's guide to the human Hsp70 family," Cell Stress \& Chaperones, vol. 1, no. 1, pp. 23-28, 1996.

[19] F. Chiappori, I. Merelli, L. Milanesi, G. Colombo, and G. Morra, "An atomistic view of Hsp70 allosteric crosstalk: from the nucleotide to the substrate binding domain and back," Scientific Reports, vol. 6, p. 23474, 2016.

[20] H. M. Beere, B. B. Wolf, K. Cain et al., "Heat-shock protein 70 inhibits apoptosis by preventing recruitment of procaspase- 9 to the Apaf-1 apoptosome," Nature Cell Biology, vol. 2, no. 8, pp. 469-475, 2000.

[21] Y. D. Zhang, Z. Zhou, L. G. Wang, and B. Huang, "Transcriptome, expression, and activity analyses reveal a vital heat shock protein 70 in the stress response of stony coral Pocillopora damicornis," Cell Stress \& Chaperones, vol. 23, no. 4, pp. 1-11, 2018.

[22] J. Kim, J. Oh, D.-H. Yoon, and G.-H. Sung, "Identification of calmodulin binding proteins in the entomopathogenic fungus Beauveria bassiana," Folia Microbiologica, vol. 63, no. 1, pp. 13-16, 2018.

[23] Y. Uemura, N. Nakagawa, T. Wakamatsu et al., "Crystal structure of the ligand-binding form of nanoRNase from Bacteroides fragilis, a member of the DHH/DHHA1 phosphoesterase family of proteins," Febs Letters, vol. 587, no. 16, pp. 2669-2674, 2013.

[24] S. Kota, C. V. Kumar, and H. S. Misra, "Characterization of an ATP-regulated DNA-processing enzyme and thermotolerant phosphoesterase in the radioresistant bacterium Deinococcus radiodurans," Biochemical Journal, vol. 431, no. 1, pp. 149-157, 2010.

[25] C. Khosla, R. S. Gokhale, J. R. Jacobsen, and D. E. Cane, "Tolerance and specificity of polyketide synthases," Annual Review of Biochemistry, vol. 68, no. 68, pp. 219-253, 1999.

[26] H. Jenke-Kodama, A. Sandmann, R. Müller, and E. Dittmann, "Evolutionary implications of bacterial polyketide synthases," Molecular Biology and Evolution, vol. 22, no. 10, pp. 20272039, 2005.

[27] F. E. Koehn and G. T. Carter, "The evolving role of natural products in drug discovery," Nature Reviews Drug Discovery, vol. 4, no. 3, pp. 206-220, 2005.

[28] B. Wawrik, L. Kerkhof, G. J. Zylstra, and J. J. Kukor, "Identification of unique type II polyketide synthase genes in soil," Applied and Environmental Microbiology, vol. 71, no. 5, pp. 2232-2238, 2005.

[29] M. M. Moake, O. I. Padilla-Zakour, and R. W. Worobo, "Comprehensive review of patulin control methods in foods," Comprehensive Reviews in Food Science and Food Safety, vol. 4, no. 1, pp. 8-21, 2005.

[30] S. M. Sanzani, M. Reverberi, M. Punelli, A. Ippolito, and C. Fanelli, "Study on the role of patulin on pathogenicity and virulence of Penicillium expansum," International Journal of Food Microbiology, vol. 153, no. 3, pp. 323-331, 2012.

[31] J. Tannous, R. El Khoury, S. P. Snini et al., "Sequencing, physical organization and kinetic expression of the patulin biosynthetic gene cluster from Penicillium expansum,"
International Journal of Food Microbiology, vol. 189, pp. 5160, 2014.

[32] J. Beck, S. Ripka, A. Siegner, E. Schiltz, and E. Schweizer, "The multifunctional 6-methylsalicylic acid synthase gene of Penicillium patulum. Its gene structure relative to that of other polyketide synthases," European Journal of Biochemistry, vol. 192, no. 2, pp. 487-498, 1990.

[33] Q. Al. Abdallah and J. R. Fortwendel, "Exploration of Aspergillus fumigatus Ras pathways for novel antifungal drug targets," Frontiers in Microbiology, vol. 6, 2015.

[34] G. Huang, Q. Huang, Y. Wei, Y. Wang, and H. Du, "Multiple roles and diverse regulation of the Ras/cAMP/protein kinase A pathway in Candida albicans," Molecular Microbiology, vol. 111, no. 1, pp. 6-16, 2019.

[35] R. J. Heath, S. Jackowski, and C. O. Rock, "Chapter 3 fatty acid and phospholipid metabolism in prokaryotes," Biochemistry of Lipids, Lipoproteins and Membranes, 4th Edition, vol. 36, pp. 55-92, 2002.

[36] L. Bernardo, C. Morcia, P. Carletti et al., "Proteomic insight into the mitigation of wheat root drought stress by arbuscular mycorrhizae," Journal of Proteomics, vol. 169, pp. 21-32, 2017.

[37] N. N. Mishra, T. T. Tran, R. Seepersaud et al., "Perturbations of phosphatidate cytidylyltransferase (Cdsa) mediate daptomycin resistance in Streptococcus mitis/oralis by a novel mechanism," Antimicrobial Agents and Chemotherapy, vol. 61, no. 4, 2017.

[38] C.-L. Wang, W.-B. Shim, and B. D. Shaw, "Aspergillus nidulans striatin (StrA) mediates sexual development and localizes to the endoplasmic reticulum," Fungal Genetics and Biology, vol. 47, no. 10, pp. 789-799, 2010.

[39] A. Viefhues, J. Heller, N. Temme, and P. Tudzynski, "Redox systems in Botrytis cinerea: impact on development and virulence," Molecular Plant-Microbe Interactions, vol. 27, no. 8, pp. 858-874, 2014.

[40] G. Ianiri, A. Idnurm, and R. Castoria, "Transcriptomic responses of the basidiomycete yeast Sporobolomyces sp to the mycotoxin patulin," BMC Genomics, vol. 17, 2016.

[41] I. G. Wool, "The structure and function of eukaryotic ribosomes," Annual Review of Biochemistry, vol. 48, no. 48, pp. 719-754, 1979.

[42] M. Sato, Y. Saeki, K. Tanaka, and Y. Kaneda, "Ribosomeassociated protein $\mathrm{LBP} / \mathrm{p} 40$ binds to $\mathrm{S} 21$ protein of $40 \mathrm{~S}$ ribosome: analysis using a yeast two-hybrid system," Biochemical and Biophysical Research Communications, vol. 256, no. 2, pp. 385-390, 1999.

[43] I. Török, D. Herrmann-Horle, I. Kiss et al., "Down-regulation of RpS21, a putative translation initiation factor interacting with $\mathrm{P} 40$, produces viable minute imagos and larval lethality with overgrown hematopoietic organs and imaginal discs," Molecular and Cellular Biology, vol. 19, no. 3, pp. 2308-2321, 1999.

[44] M. Sato, C. Jit Kong, H. Yoshida et al., "Ribosomal proteins S0 and S21 are involved in the stability of 18S rRNA in fission yeast, Schizosaccharomyces pombe," Biochemical and Biophysical Research Communications, vol. 311, no. 4, pp. 942947, 2003.

[45] F. Hannemann, A. Bichet, K. M. Ewen, and R. Bernhardt, "Cytochrome P450 systems-biological variations of electron transport chains," Biochimica et Biophysica Acta (BBA)General Subjects, vol. 1770, no. 3, pp. 330-344, 2007.

[46] K. M. Trippe, T. J. Wolpert, M. R. Hyman, and L. M. Ciuffetti, "RNAi silencing of a cytochrome P450 monoxygenase disrupts the ability of a filamentous fungus, Graphium sp., to 
grow on short-chain gaseous alkanes and ethers," Biodegradation, vol. 25, no. 1, pp. 137-151, 2014.

[47] R. Udomsinprasert, S. Pongjaroenkit, J. Wongsantichon et al., "Identification, characterization and structure of a new delta class glutathione transferase isoenzyme," Biochemical Journal, vol. 388, no. 3, pp. 763-771, 2005.

[48] D. Sheehan, G. Meade, V. M. Foley, and C. A. Dowd, "Structure, function and evolution of glutathione transferases: implications for classification of non-mammalian members of an ancient enzyme superfamily," Biochemical Journal, vol. 360, no. 1, pp. 1-16, 2001.

[49] P. D. Josephy, "Genetic variations in human glutathione transferase enzymes: significance for pharmacology and toxicology," Human Genomics and Proteomics, vol. 2, no. 1, Article ID 876940, 2010.

[50] Q. L. OuYang, N. G. Tao, and M. L. Zhang, "A damaged oxidative phosphorylation mechanism is involved in the antifungal activity of citral against Penicillium digitatum," Frontiers in Microbiology, vol. 9, 2018.

[51] J. Xue, Y. Zhang, C. Wang et al., "Effect of nutrition and environmental factors on the endoparasitic fungus Esteya vermicola, a biocontrol agent against pine wilt disease," Current Microbiology, vol. 67, no. 3, pp. 306-312, 2013.

[52] Y. Zong, B. Li, and S. Tian, "Effects of carbon, nitrogen and ambient $\mathrm{pH}$ on patulin production and related gene expression in Penicillium expansum," International Journal of Food Microbiology, vol. 206, pp. 102-108, 2015.

[53] H. L. Yang, Y. Y. Liao, J. Zhang, and X. L. Wang, "Comparative transcriptome analysis of salt tolerance mechanism of Meyerozyma guilliermondii $\mathrm{W} 2$ under $\mathrm{NaCl}$ stress," 3 Biotech, vol. 9, 2019 . 